\title{
Pandemia e dinâmica social: urgências, impasses e incertezas
}

\author{
https://doi.org/10.21814/uminho.ed.23.7
}

\section{Luís Cunha}

Luís Cunha (ORCID: 0000-0002-9940-9265) é Professor Auxiliar do Departamento de Sociologia do Instituto de Ciências Sociais da Universidade do Minho. É antropólogo e investigador do CRIA/UMinho. 
O surto pandémico que se atravessou nas nossas vidas, que as modificou de forma tão inesperada, coloca-nos desafios de natureza muito diversa. Exigiu, e exige ainda, respostas imediatas por parte dos sistemas de saúde dos diferentes países e a mais ampla mobilização da ciência na busca das soluções terapêuticas mais adequadas ao seu combate. Também a gestão política e social da crise sanitária exigiu rapidez de intervenção, tanto na definição dos serviços essenciais e na aplicação das regras de confinamento e desconfinamento, quanto na implementação de instrumentos de apoio direto e indireto a cidadãos e a empresas em dificuldade. Esta urgência, necessária e inevitável, não deve, no entanto, absorver todo o debate. A forma como surgiu, como se expandiu e como promete persistir por força dos danos que gerou, faz do SARS-CoV-2 um bom ponto de partida para pensarmos e nos interrogarmos acerca de algumas das dinâmicas da contemporaneidade. Como antropólogo, interessam-me mais as interrogações e as dúvidas que a avaliação da justeza ou do erro das respostas dadas em situação de urgência. Nesse sentido, o que aqui escreverei será guiado pela conviç̧ão de que também a incerteza pode ser fecunda, sobretudo numa matéria motivada por um vírus que não se vê, mas que promete não deixar nada intocado.

Embora sabendo que muito do que se diz e escreve por estes dias há de revelar-se inútil, extemporâneo, inadequadamente alarmista ou ingenuamente otimista num futuro próximo, é difícil olhar para lá dos sinais imediatos, dessa espécie de espuma que há meses nos vem cercando, composta por números e gráficos, por testemunhos emocionados, por projeções, ora otimistas ora pessimistas, da evolução pandémica. Importa, todavia, que façamos um esforço de ver para lá dessa espuma, pois essa é a única forma de abrir a discussão para as múltiplas dimensões do que está a suceder. Empreendimento difícil, desde logo, pelo efeito de presentismo induzido pelas modalidades dominantes de comunicação no espaço público. Seja nos media convencionais, como as televisôes e os jornais, seja nas redes sociais, dificilmente se vai além do imediato ou se ultrapassa o sintético, a condensação na nota rápida que dá conta do último acontecimento e a ele se circunscreve. Este efeito, combinado com a valorização excessiva da competência técnica - fenómeno bastante conhecido e denunciado no domínio da economia política (Cunha, 2018, p. 608) - circunscreve e limita o debate, frequentemente impedindo ou dificultando qualquer análise que vá além do óbvio. Certo de 
não encontrar respostas, comprometo-me a deixar aqui perguntas que visam contribuir para alargar o debate, projetando-o para aquele que deve ser o espaço crítico habitado pelas ciências sociais, irredutível ao imediatismo e procurando ver para lá da tecnicidade colocada por questôes específicas, sejam elas as da saúde pública stritu senso, sejam as que procuram concentrar as respostas à pandemia a partir do quadro teórico que sustenta o modelo económico dominante - tipicamente expansionista e extractivista, sem admitir alternativa.

Pode um acidente histórico, neste caso o surgimento de uma pandemia, gerar desvios ou inflexões nas relações sociais, económicas e políticas, com reflexos na nossa relação com o ambiente, na forma como trabalhamos ou mesmo nos processos de legitimação das soberanias, refazendo os vínculos entre local, nacional e supranacional? Será, pelo contrário, que rapidamente se recuperará, e eventualmente se aprofundará, o rumo que vinha sendo trilhado, reduzindo todo este tumulto a um sobressalto que não danifica nem corrompe um sistema fortemente estruturado e solidamente assente numa gestão integrada dos fluxos globais? Estas são dúvidas de amplo espectro, que transcendem a pandemia, mas que podem ser complementadas por outras de cariz mais específico e nem por isso menos importante. Como se reconfigurarão, num quadro de obrigação de distanciamento físico e restrição das interaçôes sociais, as sociabilidades que a modernidade construiu e a cultura generalizou - graças à uniformização das representações de lazer, bem-estar e fruição -, definindo modos de vida que encontraram expressão em múltiplas dimensóes do nosso quotidiano, desde a viagem turística à participação num festival de verão? O crescimento do teletrabalho, e consequente captura empresarial dos espaços habitacionais privados, pode conciliar-se com o valor atribuído ao indivíduo e à reserva da sua privacidade? As políticas de promoção do transporte público, motivadas por questóes ambientais e pelo excesso de concentração urbana, poderão manter-se num contexto de distanciamento físico? As fragilidades substanciais na resposta à pandemia, verificadas em vários países, serão suficientes para obrigar a repensar as cadeias de produção e de redistribuição de bens e serviços?

Não procurarei aqui, como já disse, encontrar respostas que não existem para perguntas fáceis de fazer. Bem sei que qualquer tentativa de resposta a estas e outras questões semelhantes, comporta, inevitavelmente, uma boa dose de especulação, armadilha que 
desejo evitar. No momento em que escrevo (final de junho de 2020), o número de pessoas contaminadas com o SARS-CoV-2 no planeta ultrapassou os dez milhóes e o número de vítimas está próximo das quinhentas mil. Estes grandes números são sempre assustadores, mas podemos relativizá-los fazendo notar que a última grande pandemia (1918-19), a pneumónica ou gripe espanhola, terá infetado cerca de quinhentos milhôes de pessoas e vitimado várias dezenas de milhões, acrescendo a esta desmesura o facto de a população mundial ser, à época, menos de um quarto da atual. Não sendo possível fazer um balanço antes da superação completa do atual surto pandémico, parece evidente, pelo menos para já, que a ameaça maior se situa nas consequências sociais e económicas resultantes do combate planetário ao vírus. Assim, para lá das incertezas que ainda se colocam em termos de saúde pública - curvas epidemiológicas diferentes em diversas regiões do planeta; possibilidade de novas ondas pandémicas; soluçôes terapêuticas ainda incertas ou parciais - é útil discutir a forma como a pandemia foi sendo vista, projetada e narrada no espaço público, atendendo, sobretudo, ao efeito de objetificação produzido pelo modo como é vista e mostrada.

A forma como a presença do SARS-CoV-2 foi vista e mostrada no momento mais alto da sua expansão pode ser balizada por duas convicções extremas, ambas projetadas nas redes sociais, visíveis em cartazes mobilizadores e também transmitidas em debates mais ou menos públicos: «vamos todos ficar bem» versus «nada voltará a ser como antes». A primeira afirmação, graficamente coroada por um icónico arco-íris, assenta num otimismo um pouco naïf, feito à margem das vítimas diretas do surto $\mathrm{e}$ desvalorizando os danos derivados, evidentes desde muito cedo e suficientes para nos impedir de imaginar um futuro imediato que não esteja assombrado pela passagem deste novo coronavírus. A segunda afirmação é bastante mais interessante, graças à ambiguidade que a enforma. Nela combina-se desânimo, ameaça e esperança, uma mistura que a torna estranhamente convincente para pessoas que se posicionam perante ela de forma muito diferente. Se há quem veja nessa suposta impossibilidade de voltar ao «que era antes» um sinal de esperança, indiciador de uma relação mais sustentável com a natureza, há também quem aponte nessa irreversibilidade um sentido de rumo bem definido politicamente, um rumo que recupera e reforça a ideia da inevitabilidade da aplicação de medidas corretivas, leitura que não remete para um futuro verdadeiramente novo, antes 
para um passado bem recente em que uma outra crise atravessou as nossas vidas. Em todo o caso, é no imenso espaço vago que liga estas duas formulações - demasiado vagas para serem úteis e demasiado incertas para orientar práticas - que me parece útil situar qualquer análise projetiva das consequências provocadas pela COVID-19.

Pela minha parte, proponho-me explorar esse espaço vago a partir de dois eixos de análise. No primeiro deles, argumentarei acerca da eficácia versus insuficiência dos topoi narrativos convocados pela pandemia. Se através deles se procurou gerar consenso, a verdade é que a sua eventual ineficácia se pode tornar num fator disruptivo, gerador de efeitos imprevistos, podendo transformar esta crise singular num poderoso revelador das insuficiências e contradições do modelo begemónico de pensamento do mundo. Não me ocuparei aqui da caracterização desse modelo, mas faço notar que a sua forte estruturação e consolidação permitiu ver nele o fim da bistória (Fukuyama, 1992), embora não falte, também, quem veja nessa solidez brechas que antecipam o seu colapso (Taibo, 2016). O segundo eixo de análise assenta numa ideia de algum modo contraintuitiva, já que me proponho pensar o surgimento deste vírus não como um evento singular e irrepetível, antes o integrando num fio temporal mais vasto. Quer isto dizer, que ao invés de ver este surto pandémico como uma manifestação conjuntural, necessariamente desagregada do sentido estrutural mais profundo que a História vem seguindo, proponho que o olhemos enquanto expressão concreta de um desequilibrio sistémico, nomeadamente o que resulta da divergência entre a lógica extractivista e o ideal de equilíbrio ambiental. Claro que é possível e razoável argumentar que a singularidade desta crise pandémica não está no surgimento de um problema de saúde pública em si mesmo, mas na resposta global que este evento gerou - confinamento, suspensão de inúmeras atividades económicas, imposição de regras rígidas no espaço público, etc. Possível, mas razoavelmente especulativa, é a discussão acerca da possibilidade de encarar as soluções encontradas pelos países como expressão de um processo mais amplo de naturalização de novas formas de organização do trabalho, de vigilância e de tecnopolitica (Parra \& Abdo, 2016; Kurban et al, 2017). Em todo o caso, esta proposta de considerar a pandemia no devir histórico que faz o humano, mas que é igualmente produzido por ele, coloca-nos, uma vez mais, perante as ideias de multidimensionalidade e complexidade. 
Em relação ao primeiro eixo de análise, a argumentação que proponho é indissociável da ideia de narrativa, no sentido proposto por William Labov: "Um método de recapitulação da experiência passada que consiste em fazer corresponder a uma sequência de eventos (supostamente) reais uma sequência idêntica de proposiçóes verbais” (Reis \& Lopes, 2002, p. 271). A convocação de um conjunto de metáforas reconhecíveis associadas a uma pandemia não surpreende, tendo em conta, desde logo, essa longa tradição de pensar as doenças recorrendo a metáforas (Sontag, 1977). Um dos efeitos deste género de associação é a prevalência de um princípio de convergência e de mobilização face a um inimigo comum, como se mostra de forma bem clara no caso da COVID-19. A guerra e seus derivados - linha da frente, mobilização, combate, estratégia, etc. - são expressão clara de uma tentativa de dar forma de combate bélico ao enfrentamento comum da doença, demarcando nitidamente um nós, entenda-se toda a humanidade, face a um outro, que além de estranho e inumano é invisível, apenas se corporalizando através de uma imagem, que sendo graficamente sugestiva, comprova claramente a sua outridade, quer dizer, a sua pertença a uma natureza que o remete para a esfera dos "radicalmente-outros" (Gil, 1994, p. 16). É a evidência desta diferença que legitima um espaço de consenso: trata-se de uma guerra face a um inimigo claramente definido, uma batalha com campos demarcados pela natureza, e por isso intransponíveis. Importa dizer que esta ideia de consenso foi reforçada por uma outra metáfora forte, glosada em vários tons: a de que «estamos todos no mesmo barco». Também neste caso se sugerem imagens fortes e facilmente reconhecíveis, por exemplo o perigo do mar encapelado que ameaça engolir-nos a todos, apelando à necessidade de trabalhar em conjunto para vencer a COVID-19, uma ameaça sem rosto cujo enfrentamento não admite dissidências.

A eficácia destas e de outras preposiçôes do mesmo género reside num mecanismo de reconhecimento narrativo, ou seja, na existência de quadros de significação suscetíveis de facilitar a ligação entre uma imagem conhecida (ameaça e união no trabalho para a vencer) a uma manifestação nova (COVID-19). Sabendo que estou a entrar num domínio assumidamente especulativo, pretendo, neste ponto, argumentar com algo que é apenas impressivo, ainda que sustentado na observação: quanto mais se progride na objetivação da crise pandémica e conhecem as suas consequências, mais claro se 
torna que a eficácia das metáforas a que aludimos resultou apenas conjunturalmente e com base num efeito meramente de especular. Assim, a evidência de que não estamos todos no mesmo barco e de que enfrentamos esta guerra com armas desiguais, dilui a ideia de consenso que estruturou a narrativa central sobre o combate à doença, desvelando o seu sentido político, tornando mais nítidos os lugares de poder e a intencionalidade das vozes que promoveram essa narrativa. Dizendo de outra forma, se a primeira fase de combate à COVID-19 se ajustou bem à ideia de guerra comum, sendo cada uma das nossas casas uma trincheira que nos protegia de um inimigo invisível e implacável, o processo de desconfinamento vem evidenciando que as consequências indiretas da pandemia, como o desemprego ou a quebra de rendimentos, são muito diferenciadas socialmente, facto que conduz a uma menor eficácia das narrativas que sublinham o consenso.

São incertas as consequências desta perceção da diferente exposição em que nos encontramos face a uma causa que é externa ao normal funcionamento do sistema económico. Em crises precedentes, algumas dessas diferenças foram exponenciadas e outras disfarçadas, por forma a gerar o menor dano possível no sistema enquanto tal. Assim, nas recentes crises financeiras, vimos como o reforço de algumas segmentaçóes sociais permitiu reorientar a tensão para a periferia do núcleo crítico, ou seja, afastando-a da responsabilização do sistema financeiro pelo colapso. Efeito conseguido, também naquele caso, através do recurso a narrativas reconhecíveis e mais ou menos consensualizadas - os jovens precarizados face aos velhos beneficiando de pensóes estáveis; os empreendedoristas face aos passivos e dependentes, etc. Nas crises de 2008 e 2011 assistimos à eficácia de um mecanismo de reorientação do olhar e de construção narrativa que iludiu o carácter sistémico da crise, colocando o foco em segmentos menores do sistema, sobretudo em fraturas facilmente exploráveis no plano emocional.

Na situação presente é percetível a emergência de algumas narrativas de natureza semelhante, a mais expressiva das quais assenta na distinção entre setor público e privado, o primeiro supostamente protegido pela tutela do Estado e o segundo deixado à mercê de várias volatilidades, que tanto podem resultar da agitação do sistema financeiro como de uma pandemia, como neste caso sucedeu. A hipótese de que este género de reorientação possa ser menos eficaz agora que em situações precedentes, prende-se com 
a diferente natureza da atual crise. Igualmente geradoras de desemprego, de quebras de rendimento e do colapso de segmentos da atividade produtiva, as crises precedentes - subprime, sistema financeiro e dívidas soberanas, para ficarmos por manifestações recentes do fenómeno - podem e devem ser vistas como sistémicas, o que significa que mesmo sendo imprevistas na sua temporalidade concreta são expectáveis, e por isso mesmo controláveis a partir de mecanismos intrínsecos ao sistema. Neste sentido, uma crise sistémica pode ser vista como funcional, na medida em que permite um arrefecimento de sistemas sobreaquecidos, por exemplo pelo crescimento incontrolado das imparidades ou pela ingovernabilidade de instrumentos financeiros. É diferente desta vez, o que legitima a hipótese - especulativa, mas sobre a qual parece útil refletir - de que a natureza assistémica da crise provocada pela COVID-19 transporta consigo um elevado potencial de desocultação de mecanismos de poder habitualmente discretos ou escondidos. O argumento é, então, o de que o carácter ideológico das escolhas políticas, frequentemente oculto por topoi narrativos como os da inevitabilidade, da meritocracia ou do funcionamento do mercado como expressão da natureza racional dos sujeitos, pode ser mais desvelado agora que em crises precedentes, exatamente por ser mais difícil aplicar, desta vez, os mesmos instrumentos de ocultação. A natureza da atual crise, exógena a quaisquer práticas ou competências económicas, não permite explicar a maior exposição de populaçôes pobres ou de minorias étnicas à doença nem às suas consequências - quebra de rendimento, desemprego, acentuação das desigualdades senão recorrendo a fatores sociais e políticos. Dizendo de outra forma, perante uma crise para cuja explicação não concorrem narrativas de culpabilidade («andámos a viver acima das nossas possibilidades») ou de meritocracia (Europa do Norte em confronto com a do Sul, entre outras variantes), os vetores políticos e ideológicos tenderão a ganhar maior presença, o que acentuará o seu potencial disruptivo.

O que estou a sugerir, sempre tendo em conta as limitações de uma análise como esta, elaborada dentro de um ciclo pandémico de resultado incerto, é a possibilidade de que no âmbito da atual crise se venha a desenvolver uma lógica confrontacional que tem sido evitada em crises precedentes. Não se trata de recuperar a luta de classes nos seus moldes tradicionais, mas de observar como a ideia de confronto se evidencia: a partir dos novos agentes gerados por uma economia assente na precarização dos vínculos e, 
também, a partir da constante compressão dos rendimentos do trabalho face à remuneração do capital. De algum modo, trata-se de admitir o redireccionamento da metáfora da guerra para o interior do sistema, substituindo o princípio de união e consenso em torno do combate ao SARS-CoV-2, pela definição de um adversário interno, exatamente aquele que alimenta as desiguais consequências da doença no tecido social. É neste sentido que acima referia a desocultação: efeito secundário de uma crise sanitária, que vem tornar (mais) visíveis as contradiçôes que estruturam o modelo social, político e cultural hegemónico, estrutura complexa e multiforme, que podemos designar, ainda que de forma algo imprecisa, por modelo neoliberal.

A centralidade do papel do Estado na resposta à atual crise, face ao modelo de diminuição do seu papel através do processo de privatização do comum, é uma dessas contradições. A indispensabilidade do Estado decorre não tanto da sua capacidade de mobilizar recursos - a necessidade de estabelecer Parcerias Público-Privadas (PPPs) evidencia uma disponibilidade financeira privada que os estados alegam não possuir mas de o poder (e dever) fazer sem expectativa de retorno. Este fator, que distingue a intervenção social garantida pelo Estado, da lógica empresarial, que em muito casos se alimenta também do comum através de formas de apropriação consentidas pelo Estado, reporta ao nível de liberalização da economia e aos consequentes efeitos na capacidade de responder às necessidades - veja-se, tipicamente, o confronto entre o modelo europeu e o prevalecente nos EUA. Se colocarmos a questão a partir das narrativas que circulam no espaço social, facilmente percebemos que a prevalência do Estado na resposta à pandemia contraria uma linha de pensamento hegemónica nos discursos produzidos a partir do setor financeiro mas disseminados de várias formas no espaço social: a vantagem da expansão da oferta privada de bens e serviços em todos os setores e subsetores, incluindo a saúde pública.

Há uma outra contradição, esta de natureza diferente, que parece igualmente ter ficado já exposta durante esta crise. Falo do conflito entre o apelo ao consumo, entendido como motor indispensável da saúde de qualquer economia e a necessidade de retração ou direcionamento de alguns consumos por razóes ambientais - por exemplo os combustíveis fósseis, mas não só - de acordo com discursos que vão fazendo o seu caminho, mesmo dentro do pensamento mainstream. Note-se que o problema e o 
perigo que pretendo evocar não é de natureza macroeconómica, ou seja, nada tem a ver com a afetação do ciclo económico devido à contração conjuntural decorrente de uma menor procura. $\mathrm{O}$ aspeto que pretendo sublinhar é o do entendimento de que é possível consumir de forma diferente sem que isso ponha em causa o bem-estar do consumidor. Na decorrência desta ideia, a hipótese de trabalho que aqui se coloca é a de a pandemia ter contribuído para revelar o mecanismo de alienação indispensável ao funcionamento do sistema. De algum modo é ainda de um fenómeno de desocultação que se trata, um efeito de revelação que toca em pontos sensíveis da arquitetura do sistema - crescimento económico como uma constante; mercados naturalmente elásticos graças ao perpétuo nascimento de novas necessidades; virtude das economias globais e dos mercados deslocalizados. Na verdade, com base no que é possível observar, devemos evocar, em relação a este assunto, dois aspetos merecedores de aprofundamento. $\mathrm{O}$ primeiro centra-se no ajustamento dos circuitos de distribuiçãa e nas práticas de consumo suscitados pelo confinamento, e o segundo reporta ao processo de relativização da importância dos vários segmentos de mercado, igualmente decorrente dos efeitos do confinamento.

No primeiro caso, a crise pandémica veio comprovar a exequibilidade de propostas, ainda minoritárias, mas que estavam já em expansão, exatamente as que apontam a vantagem de promover circuitos mais curtos de distribuição e consumo, valorizando os recursos locais na tentativa de diminuir a pegada ecológica. As questóes de soberania alimentar e de autossuficiência dos países têm vindo igualmente a ser levantadas e devem ser consideradas neste mesmo plano, muito embora exista o risco do seu aproveitamento por movimentos nacionalistas, nomeadamente quando recorrem a discursos apelando ao fechamento dos países. O segundo aspeto prende-se com a evidência do valor social de consumos agregadores e potenciadores de sociabilidades, como são os produzidos pela indústria cultural e de entretenimento, área relativamente à margem do processo de financeirização da atividade económica, e seguramente distanciada dos circuitos centrais de distribuição de recursos públicos e das narrativas que os legitimam. Se a pandemia mostrou uma certa marginalização dos profissionais ligados às artes, observável pela falta de apoios públicos à evidente quebra de atividade, a situação pré-pandémica dava conta de uma crescente tendência de captura da produção artística 
e de entretenimento pelas grandes estruturas de produção e distribuição de conteúdos. Entre estes dois sinais contraditórios, o surto pandémico revalorizou uma utilidade antiga e conhecida da atividade artística, mas de algum modo capturada pela hegemonia $\mathrm{da}$ visão racional-instrumental, que a reduziu a um produto indistinto. $\mathrm{O}$ meu argumento, portanto, é o de que a pandemia ajudou a tornar evidente que a cultura possui uma capacidade singular de unir e criar sentido de pertença, qualidade que a desagrega, pelo menos parcialmente, do domínio estritamente mercadológico, contribuindo, nesse sentido, para lhe devolver a função de instrumento essencial na criação de um sentido de comunidade e de partilha.

Pretendo focar-me agora no segundo eixo de análise acima referido, ou seja, ensaiar um modelo de observação que considera a COVID-19 a partir de um outro ângulo. Até este ponto, fiz assentar a discussão da emergência e dos efeitos da pandemia na possibilidade de a partir deles se poder gerar a erosão de algumas das práticas e das narrativas que suportam um sistema ideológico que se foi tornando hegemónico ao longo das últimas décadas. Justifiquei essa possibilidade na singularidade da crise que estamos a viver, argumentando que essa singularidade a torna irredutível ao modelo habitual de gestão das crises sistémicas e cíclicas. O foco que agora proponho projeta a COVID-19 no fio do tempo, quer dizer, considera o evento não na sua singularidade, mas como parte de um processo que se liga, mesmo que de forma indireta, a vários desequilíbrios sistémicos. O SARS-CoV-2 é o terceiro coronavírus com potencial pandémico a manifestar-se neste século. Foi antecedido pelo SARS-CoV (2002) e pelo MERS-CoV (2012), sendo ainda de referir vários surtos epidémicos de Ébola na África Ocidental e manifestações particularmente agressivas de Zica no Brasil (2015). Embora não seja possível tirar conclusões definitivas a partir destes casos, alguns estudos vêm apontando a diminuição dos habitats animais como uma das explicações para o crescimento das contaminações de humanos com vírus endémicos noutras espécies (Zohdy et al, 2019). Dando substância a esta focalização, do que se trata é de considerar o conflito concreto entre um modelo expansionista, assente no consumo de recursos não renováveis, e as suas consequências ambientais. Por esta razão, e sem deixar de ser um evento singular, a COVID-19 ganha em ser encarada como manifestação que ultrapassa essa singularidade e se inscreve no processo histórico enquanto constructo do humano. Esta colocação 
da pandemia no fio do tempo tem uma dupla consequência: responsabiliza-nos enquanto coletivo e mostra-nos a fragilidade de uma estrutura de relação que assenta na exponenciação dos processos extractivistas, ambientalmente danosos, mas inevitáveis por via das interaçóes globais em que se fundam. Se enquanto atores, simultaneamente produtores e consumidores, o desafio é o de alterar comportamentos, no que diz respeito aos processos económicos globais a situação é mais complexa. Basta ver, como já referi, que a defesa do retorno a um modelo de autossuficiência das nações (debate estimulado também pela pandemia), alimenta e é alimentado por retóricas nacionalistas de natureza autoritária e populista.

Além da tensão entre as dinâmicas extractivistas e os (des)equilíbrios ambientais que ajuda a revelar, a pandemia oferece-se ainda como boa metáfora para nos pensarmos enquanto sociedade. A expansão do vírus SARS-CoV-2 e a sua conversão em pandemia não podem ser desligadas de um mundo globalizado, onde a circulação de pessoas, de bens e também de ideias se faz rapidamente, muitas vezes de forma viral. Por essa razão, os conceitos de pandemia e de contágio são úteis para pensar os processos sociais contemporâneos, revelando a urgência da discussão em torno de alguns agentes infeciosos e de quem os controla. Falo, evidentemente, da combinação da velha Galáxia Gutenberg (McLuhan, 1962) e da nova e sempre renovada Galáxia Internet, na construção e manutenção daquilo a que Castells (1996, p. 22) chama capitalismo informacional. Neste domínio, a COVID-19 não trouxe nada de novo, embora tenha acentuado tendências e fomentado debates, nomeadamente quanto à natureza da relação entre local e global. A circulação e manipulação da informação; o papel das instituições supranacionais, como a Organização Mundial de Saúde; a utilização de redes informacionais na criação de modelos de cooperação local e a dependência dos operadores de telecomunicaçóes, foram alguns dos tópicos desse debate. Por outro lado, a exigência de confinamento acentuou e tornou mais nítidas tendências há muito iniciadas. O teletrabalho e a aquisição remota de bens e serviços são, talvez, a face mais visível de um processo que transporta consigo uma inevitável transfiguração da nossa relação com o trabalho - incorporação de postos de trabalho no espaço privado; dispensa de trabalhadores, por exemplo em linhas de caixa; necessidade de novos profissionais em atividades de entrega de produtos no domicílio; diminuição da atividade ligada à restauração, etc. 
Para lá dos processos históricos de longo alcance e do efeito que um acontecimento neles pode produzir, importa perceber os mecanismos de reconhecimento e naturalização desse acontecimento, por muito singular que ele se apresente. Assim, os processos de ressignificação da experiência social induzidos pela pandemia, mesmo os que experimentámos pela primeira vez, necessitaram do amparo de um sentido reconhecível, que pode ter na base não o experimentado, mas o imaginado. Veja-se como o tempo de confinamento que vivemos se ajusta a uma narrativa pós-apocalíptica de cariz distópico que não nos é estranha enquanto representação: ruas desertas; cidadãos em filas disciplinadas, esperando a sua vez para obter alimentos e medicamentos essenciais; viaturas policiais circulando em estradas vazias, emitindo avisos sonoros apelando à permanência em casa; parlamentos e governos aprovando sucessivos estados de emergência, suportados em consensos alargados e na ausência ou silenciamento de quaisquer contestações. Mesmo o regresso a uma certa normalidade desconfinada não reverteu completamente o cenário pós-apocalíptico em que mergulhámos. Em alguns lugares do mundo usam-se já aplicações informáticas que asseguram a vigilância dos cidadãos com o argumento da proteção de futuros contágios, e noutros lugares, inclusive entre nós, discute-se a virtude da aplicação de instrumentos semelhantes. Mesmo sem essa aceleração distópica, que tem algo de pós-bumano, observa-se a exigência do uso generalizado da máscara, renovam-se as recomendaçóes de distanciamento social e multiplicam-se as explicaçôes acerca das regras de conduta que devemos seguir caso queiramos frequentar algum dos vários espaços onde a vida comum decorre.

Se a sugestão pós-apocalíptica remete para a ideia de um outro tempo, ou talvez, dizendo melhor, para o fim de um tempo e a inauguração de um outro, a nossa experiência do espaço alterou-se também de forma significativa neste período. $\mathrm{O}$ mundo continua a caber num único ponto, na condição de esse ponto se encontrar numa qualquer plataforma eletrónica, já que ao nível da experiência física prepondera a distensão, como se a presença do vírus tivesse dilatado o espaço que nos cerca. É-nos imposta, hoje, uma maior distância entre os corpos, de acordo com um critério epidemiológico universal, o que nos obriga a discutir a etiqueta culturalmente convencionada, aquilo a que Edward T. Hall (1966) chamou proxémia. O efeito de distensão do espaço é também sentido no condicionamento à circulação e à viagem, igualmente domínios 
marcantes da nossa experiência quotidiana. A promessa de um mundo condensado num ponto restringe-se, portanto, ao domínio do virtual, transformando uma utopia feita do encanto da viagem, da fecundidade dos encontros e da democratização do lazer, numa distopia, caracterizada pelo distanciamento, pelo confinamento, também pela restrição dos contactos e pela suspensão de muitos dos prazeres a que nos habituámos. Se a modernidade tardia alterou as coordenadas espácio-temporais pelo encolhimento do mundo, o surto pandémico sugere uma revisão desse processo pela forma como recoloca o debate entre globalização e individualização: o mundo dilatou-se no sentido em que a dificuldade de deslocação deixou tudo mais distante, sendo certo que, a um outro nível, acentuou o encolhimento, sobretudo graças ao fomento ou mesmo inauguração de novas formas de comunicação, por exemplo do domínio da educação. Em todo o caso, a estabilidade de um processo social que parecia inatacável vacilou, e se é certo que o risco foi desde cedo associado a essa modernidade tardia (Beck, 1986), a COVID-19 mostrou como o medo pode assumir um peso decisivo, obnubilando qualquer ideia de termos chegado a um modelo social estável e imune a sobressaltos históricos.

A duração e a profundidade dos efeitos da pandemia são ainda muito incertas. Percebê-la em andamento cria um efeito de esbatimento que dificilmente nos permite destacar os sinais mais relevantes. Olhada a partir dos lugares de confinamento, a pandemia revelou um medo insidioso que fomentou o desejo de distanciamento, ao mesmo tempo que produzia relatos de proximidade e cooperação. Soubemos de vizinhos que se disponibilizaram a fazer compras para quem não podia sair de casa e assistimos à criação de redes espontâneas de oferta de alimentos aos mais necessitados. Vimos também, e em sentido inverso, como o medo gerou sentimentos odiosos, de denúncia e exigência de afastamento de vizinhos considerados «perigosos» pelos comportamentos que adotavam ou mesmo pela profissão que exerciam. A experiência do local, feita à margem de qualquer tutela institucional, mostrou-se capaz de dispensar instrumentos convencionais de apoio, mas mostrou também o pior que pode emergir na ausência de regulação e controlo.

Por outro lado, no plano oposto, os sinais foram igualmente contraditórios. Olhada na esfera global, a pandemia apenas gerou convergência relativa, base para a 
construção de uma narrativa centrada na metáfora de uma guerra planetária e civilizacional: o vírus visto como inimigo da humanidade, que só pode ser enfrentado em conjunto e através de instrumentos de combate que nos definem enquanto humanos, como é o caso da ciência. Porém, no que diz respeito aos atos concretos, o que prevaleceu foi o confronto entre países, tanto pela comparação da eficácia de resposta dos respetivos serviços públicos de saúde, como pela discussão das estratégias de contenção epidemiológica que foram adotadas. Embora percebendo, desde cedo, que estávamos perante um problema comum, as respostas oscilaram entre o egoísmo e o apoio solidário, raras vezes se observando uma verdadeira comunhão de interesses, menos ainda o esforço para a definição de uma estratégia comum. A falta de equipamento médico e a impossibilidade de o obter em tempo útil, lançou o debate acerca da autonomia dos países nessa matéria, mas depressa esse debate se alargou, levando algumas vozes a defender a necessidade de reindustrialização dos espaços nacionais. Por outro lado, as economias nacionais excessivamente centradas na gestão de crédito e dívida revelaram dificuldade acrescida na resposta às solicitações colocadas por uma crise com estas características. Este facto abriu uma outra frente de debate, nomeadamente no contexto da União Europeia, acerca dos mecanismos de solidariedade entre estados, prolongando, em outros moldes, um confronto que ficara já evidente aquando da crise financeira precedente.

A insuficiência das respostas institucionais, a falta de solidariedade entre países e a forma como a pandemia se expandiu de forma descontrolada, são fatores que fragilizaram os processos de globalização, ao mesmo tempo que os anúncios de colaboração na procura de uma vacina parecem aprofundar a cooperação internacional. À margem da procura de soluçóes no campo da saúde pública, a restrição de circulação de pessoas e de bens veio chamar a atenção para o risco de colapso no abastecimento de bens essenciais em consequência de uma crise com as características da atual. Sendo igualmente incertas as marcas deixadas pela perceção deste risco, emergem alguns discursos que questionam o modelo de especialização económica das nações, sobretudo nos casos em que essa especialização implica menor resiliência perante fenómenos extremos. É fácil perceber o risco acrescido num país como Portugal, com uma economia bastante dependente da exportação de serviços, sobretudo pelo enorme peso desempenhado pelo turismo nesses serviços. Num cenário como este, a suspensão duradoura da 
atividade turística exporia a economia nacional de forma dramática, gerando acentuado desemprego e enormes quebras de rendimento. $\mathrm{O}$ surto pandémico permitiu perceber que qualquer interrupção da circulação de bens essenciais expõe a fragilidade de uma economia-mundo, essa mesma que parecia coroar o fim da história. As soluções para esta fragilidade parecem ainda, nesta fase, estar mais suportadas na retórica que em propostas estruturadas. É o que se passa com a sugestão de reindustrialização, havendo outras, talvez até com maior lastro histórico, que ganharam visibilidade acrescida nesta fase, como é o caso dos programas de fomento agrícola ou de garantia de manutenção e reforço da soberania alimentar.

Este breve olhar, meramente impressivo, sobre a pandemia e aquilo que a cerca, permite-nos perceber como a tensão entre solidariedade e competição se revelou, até agora, como o sinal mais marcante da passagem do SARS-CoV-2. Procurando antecipar o que se segue, vale a pena reiterar o que acima já se sugeriu: se a solidariedade local evidenciou a importância da proximidade e da empatia, as consequências económicas e sociais da pandemia poderão gerar o efeito inverso, revelando níveis de exposição muitos diferenciados à crise. $\mathrm{O}$ desemprego, o crescimento das dívidas públicas em países mais expostos e as consequentes medidas de austeridade, terão sempre um potencial aproveitamento político, que pode alimentar os populismos emergentes ou já afirmados (Laclau, 2007). A um outro nível, a facilidade com que o medo se difundiu parece abrir portas ao consentimento de medidas restritivas da liberdade, quer as que se expressam através de instrumentos jurídicos já disponíveis, como o estado de exceção, em processo de franca banalização (Agamben, 2003), quer as que poderão decorrer de mecanismos de vigilância digital, alguns já em aplicação e outros em estudo. Será no equilíbrio, ou desequilíbrio, usado na aplicação destas medidas que se jogará muito do nosso futuro comum.

Procurando ver além da pandemia, mas inscrevendo a projeção de dinâmicas futuras na sombra da sua passagem, talvez possa dizer-se que a mobilização cidadã será decisiva no confronto entre o fortalecimento dos princípios republicanos de governação democrática ou a captura das instituições por pulsóes de outra natureza. Falo de formas de mobilização a partir da base, experimentadas também em tempo de pandemia, mas observáveis desde há muito em movimentos sociais de diferente natureza. Uma natureza que não só é diferente como é incerta, o que confere a essas mobilizações 
de base contornos potencialmente disruptivos, tanto quanto reforçam o nacionalismo, como quando se distanciam da segmentação do espaço social em estados-nação. Se o nacionalismo, aliado ao populismo, significa uma visita intempestiva e anacrónica à génese da aliança entre soberanias liberais e modo de produção capitalista, os processos de segmentação obrigam a repensar as fronteiras e os vínculos políticos, sociais e culturais que veem ligados os cidadãos aos territórios. O que sobra, feitas as contas, é um mar de espuma após o rebentar de uma primeira onda, sem que saibamos se outras se lhe seguirão. Sabemos, isso sim, que nem tudo ficará bem no final da história, sabendo também, e em compensação, que por mais profunda que tenha sido esta onda que nos atingiu, ou mesmo outras que a ela se sigam, o que houver de diferente não está inscrito na pedra como uma fatalidade. É a nós que cabe (re)construir a vida comum quando a pandemia se tornar em sujeito histórico. Devemos fazê-lo sem esquecer como ela marcou a nossa vida, mas tendo sempre presente o muito que com ela aprendemos e estamos ainda a aprender.

\section{BIBLIOGRAFIA CITADA}

Amgaben, Giorgio (2003), Estado de Excep̧̧ão, Lisboa, Edições 70, 2015.

Beck, Ulrich (1986), La Société du Risque. Sur la voie d'une autre modernité, Paris, Flammarion.

Calado, Virgínia \& Cunha, Luís (2018) "Economic crisis and political decision: words and meaning”. in Changing Societies: Legacies and Challenges. Vol. II. Citizenship in Crisis, e-book, eds. M. C. Lobo, F. C. da Silva and J. P. Zúquete, Lisboa, Imprensa de Ciências Sociais, pp. 87-109.

Castells, Manuel (1996), A Sociedade em Rede, vol.1, Lisboa, Fundação Calouste Gulbenkian, 2002.

Cunha, Luís (2018), "Entre desespero e utopia: três fragmentos para um retrato em movimento”, in Sílvia Gomes et al (org.), Desigualdades Sociais e Politicas Públicas. Homenagem a Manuel Carlos Silva, Vila Nova de Famalicão, Húmus, pp. 605-617, 2018. ISBN: 978-989-755-381-3.

Dardod, Pierre \& Laval, Christian (2015), A Nova Razão do Mundo. Ensaio Sobre a Sociedade Neoliberal, São Paulo, Boitempo.

Fukuyama, Francis (1992), O Fim da História e o Último Homem, Lisboa, Gradiva.

Gil, José (1994), Monstros, Lisboa, Quetzal Editores.

Hall, Edward T. (1966), A Dimensão Oculta, Lisboa, Relógio d’Água, 1986. 
Hannerz, Ulf (1997), Fluxos, fronteiras, híbridos: palavras-chave da Antropologia, Mana, 3(1), pp. 7-39.

Harvey, David (2014), Seventeen Contradictions and the End of Capitalism, London, Profile Books.

Ingold, Tim \& Palsson, Gisli (eds.) (2013), Biosocial Becomings. Integrating social and biological anthropology, Cambridge University Press.

Kurban, Can; Peña-López, Ismael \& Harber, Maria (2017), What is technopolitics? A conceptual schema for understanding politics in the digital age, IDP - Revista D'Internet, Dret I Politica, no24, Universitat Oberta de Catalunya, pp. 3-20.

Laclau, Ernesto (2007), La Razón Populista, Buenos Aires, Fondo de Cultura Económica.

McLuhan, Marshall (1962), A Galáxia Gutenberg: a formação do homem tipográficos São Paulo, Companhia Editora Nacional, 1977.

Morton, Timothy (2013), Hyperobjects. Philosophy and Ecolog $1 y$ after the end of the world, Minneapolis, University of Minnesota Press.

Parra, Henrique Z.M. \& Abdo, Alexandre Hannud (2016), Tendências democráticas e autoritárias, arquiteturas distribuídas e centralizadas, Liinc em Revista, Rio de Janeiro, v.12, no2, pp. 334-349.

Reis, Carlos \& Lopes, Ana Cristina M. (2002), Dicionário de Narratologia, Coimbra, Almedina.

Singer, Peter (2000), Escritos Sobre Uma Vida Ética, Lisboa, Dom Quixote, 2008.

Sobral, José Manuel; Lima, Maria Luísa; Castro, Paula \& Sousa, Paulo Silveira e (org.) (2009), A Pandemia Esquecida. Olhares comparados sobre a pneumónica 1918-1919, Lisboa, Imprensa de Ciências Sociais.

Sontag, Susan (1977), A Doença Como Metáfora e A Sida e as Suas Metáforas, Lisboa, Quetzal Editores, 1998. Taibo, Carlos (2016), Colapso. Capitalismo terminal, transição ecossocial, ecofascismo, Lisboa, Letra Livre, 2019. Zohdy, Sarah; Schwartz \& Oaks, Jamie R (2019), The Coevolution effect as a driver of spilover, Trends in Parasitology, vol. 25, Issue 6, pp. 399-408. 